\title{
$\square$ Additional acute improvement in left ventricular function after solving residual mechanical dyssynchrony in cardiac resynchroni- zation patients
}

\author{
Jana Ljubas Maček, \\ Vlatka Rešković \\ Lukšić, \\ Marijan Pašalić, \\ Marija Brestovac, \\ Borka Pezo Nikolić, \\ Martina Lovrić Benčić, \\ Jadranka Šeparović \\ Hanževački
}

University of Zagreb School of Medicine, University Hospital Centre Zagreb, Zagreb,

Croatia

RECEIVED:

March 11, 2017

ACCEPTED:

April 6, 2017

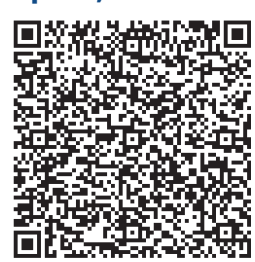

KEYWORDS: hypereosinophilic syndrome, cardiac thrombus, echocardiography. CITATION: Cardiol Croat. 2017;12(4):142-143. | https://doi.org/10.15836/ccar2017.142

*ADDRESS FOR CORRESPONDENCE: Jana Ljubas Maček, Klinički bolnički centar Zagreb, Kišpatićeva 12, HR-10000 Zagreb, Croatia. / Phone: +385-91-4488-351 / E-mail: janaljubas@yahoo.com

ORCID: Jana Ljubas Maček, http://orcid.org/0000-0001-7171-2206 • Vlatka Rešković Lukšić, http://orcid.org/0000-0002-4721-3236 Marijan Pašalić, http://orcid.org/0000-0002-3197-2190 • Marija Brestovac, http://orcid.org/0000-0003-1542-2890 Borka Pezo Nikolić, http://orcid.org/0000-0002-0504-5238 • Martina Lovrić Benčić, http://orcid.org/0000-0001-8446-6120 Jadranka Šeparović Hanževački, http://orcid.org/0000-0002-3437-6407

IIIIIIIIIIIIIIIIIIIIIIIIIIIIIIIIIIIIIIIIIIIIIIIIIIIIIIIIIIIIIIIIIIIIIIIIIIIIIIIIIIIIIIIIIIIIIIIIIIIIIIIIIIIIIIIII

Background: After cardiac resynchronization therapy (CRT), AV delay is usually set by "out of box" value while optimal VV interval is set using intracardiac electrocardiogram method (IEGM) according to the narrowest QRS width (Figure 1), regardless of the actual mechanical response of the left ventricle (LV)., ${ }^{1,2}$ Our aim was to assess the presence of residual mechanical dyssynchrony after IEGM device optimization using echocardiographic parameters and to define echocardiographic and functional response in patients with early echo-guided optimization ("zero" OPT).

Patients and Methods: 98 CRT patients (Pts), with native LBBB, were included in the study. Early post implantation IEGM device optimization was performed in all Pts followed by „zero"-OPT prior to discharge in only 44 Pts - group 1. Other 54 Pts formed the control group - group 2. In Group 1, LV preexcitation (in sequential 10 ms intervals) was modified according to the presence of early presystolic septal motion („septal flash"), LV ejection fraction (LVEF) and global longitudinal strain (GLS). Pts were followed for one year after CRT implantation and their functional capacity was evaluated using six-minute walk test/stress test/cardiopulmonary stress test. They were classified into NYHA class according to the results of the testing. The same functional evaluation was performed prior to CRT implantation in all Pts.

Results: There was no difference in mean biventricular paced QRS duration between the groups before CRT-optimization: group 1 vs. group 2 - 169,7 vs 177,9 ms, as well as after one year follow-up - 134,3 vs 137,6 ms, with no difference in biventricular pacing rate - 98,4 vs 97,7\%. Mean IEGM VV delay was 16 ms, after "zero" OPT mean VV delay was significantly prolonged to $36 \mathrm{~ms}$ ). Interventricular mechanical delay (IV MD) also has not been changed significantly (mean 35,3 vs 30,0 ms). Mean IEGM AV delay (112 ms) was very slightly modified to mean SAV of 115 ms. Early after implantation diastolic dysfunction was mostly grade 1 ( $77 \%$ Pts), with grade 2 present only in $11.7 \%$ and grade 3 in $8.8 \%$. Mean E/e' ratio was 14 with diastolic filling time corrected for RR interval 43.1 $1.6 \%$. In the group 1, after IEGM optimization

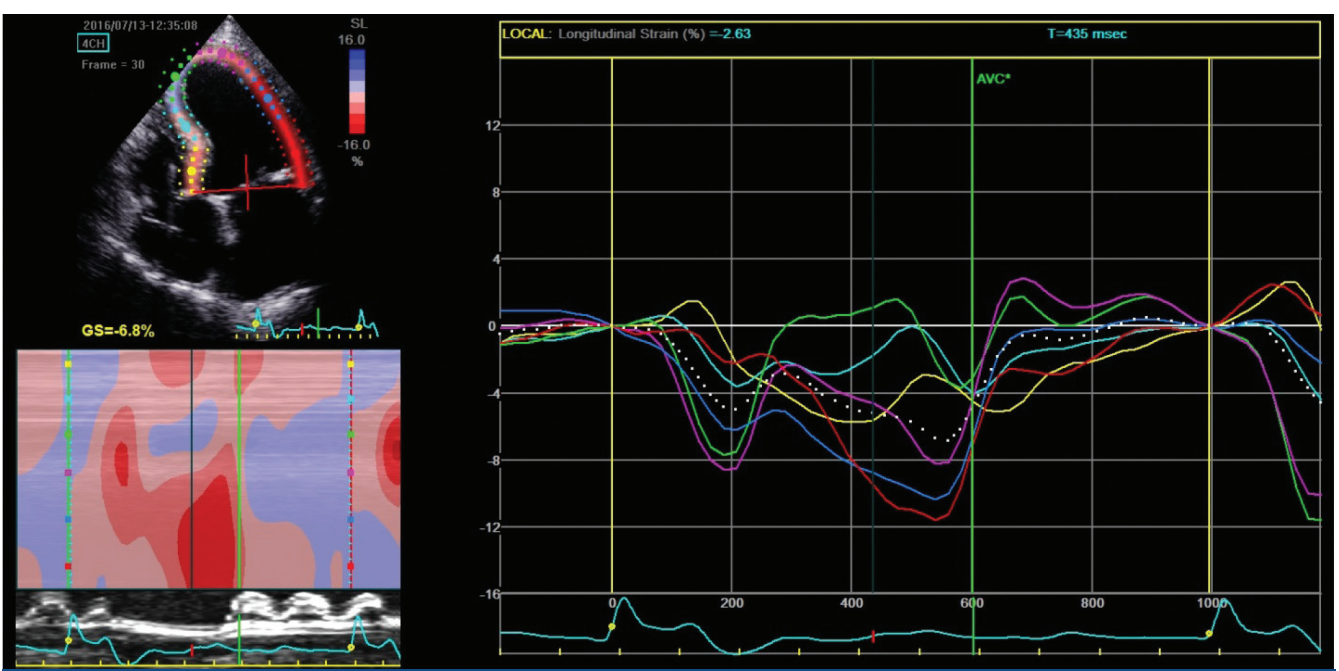

FIGURE 1. Global longitudinal strain in a patient after IEGM-based device optimization is severely reduced to $-6.8 \%$. 
Additional acute improvement in LV function after solving residual mechanical dysynchrony in cardiac resynchronization patients

$55.2 \%$ of Pts still had the presence of septal flash, $62 \%$ had prolonged septal-to-posterior wall mechanical delay ( $\geq 130 \mathrm{~ms}$ ) and $59 \%$ prolonged tissue-doppler septal-to-lateral delay (SL delay $\geq 60 \mathrm{~ms}$ ). Statistically significant improvement after "zero" OPT in many echocardiographic parameters was proven - for LV EF (before vs after 28,0 vs 31,1 \%), LVESV (173,2 vs 162,5 ml), GLS (-7,55 vs -8,78), LVOT VTI (13,5 vs 15,7 cm), LV ET (250 vs $272 \mathrm{~ms}$ ) and other. In all Pts functional improvement in NYHA class was revealed during follow up. However, in spite of very good hemodynamic response, significant difference in functional improvement between group 1 and group 2 was not reached.

Conclusion: Significant number of our patients after the first IEGM-based device optimization still has the presence of septal flash with its unfavourable consequences of intraventricular mechanics. In a great percentage of our patients residual septal-to-posterior mechanical delay was also found. LV intraventricular dyssynchrony represented the most important type of residual dysynchrony in our study that required significant change in initial VV delay (pacing interval between left and right lead) in most Pts. In our study we found that in spite of optimal paced QRS width, the majority of the patients still have unsatisfactory mechanical response that could be improved by echocardiography-based CRT optimization immediately after implantation, in order to attain the precise mechanical synchrony of LV wall motion followed by reverse remodelling of the LV.

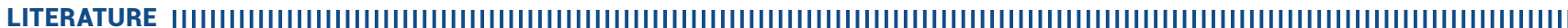

1. Lafitte S, Reant P, Zaroui A, Donal E, Mignot A, Bougted H, et al. Validation of an echocardiographic multiparametric strategy to increase responders patients after cardiac resynchronization: a multicentre study. Eur Heart J.2009 Dec;30(23):2880-7. https://doi.org/10.1093/eurheartj/ehn582

2. Wang D, Yu H, Yun T, Zang H, Yang G, Wang S, et al. Long-term clinical effects of programmer-guided atrioventricular and interventricular delay optimization: Intracardiac electrography versus echocardiography for cardiac resynchronization therapy in patients with heart failure. J Int Med Res. 2013 Feb;41(1):115-22. https://doi.org/10.1177/0300060512474570 